\title{
Applications using an Annular Four-Channel Silicon Drift Detector
}

\author{
R. Terborg, A. Käppel, T. Salge \\ Bruker AXS Microanalysis GmbH, Schwarzschildstr. 12, 12489 Berlin, Germany
}

Silicon Drift Detectors (SDDs) have become the standard detectors for energy dispersive x-ray detection in the last few years. High resolution type SDDs have an energy resolution down to $123 \mathrm{eV}$ or better at Mn-K $\alpha$. They also have a good low-energy performance down to energies about $90 \mathrm{eV}$ $(\mathrm{Si}-\mathrm{Ll} / \eta)$ and show undistorted Gaussian peak shapes with an energy resolution of $\leq 54 \mathrm{eV}$ at F-K $\alpha$ and $\leq 46 \mathrm{eV}$ at $\mathrm{C}-\mathrm{K} \alpha$. Optimized electronics maintain this energy resolution even for count rates up to $100 \mathrm{kcps}$ input count rate.

A special configuration has recently been developed for certain applications in order to improve certain limitations: Multiple element SDDs with four separate detectors integrated onto one chip but with separate electronics, provide even higher count rates through increased active area without increasing pile-up or dead time [1,2].

A special multi element concept is the QUAD XFlash 5060 (Fig. 1), an annular detector which can be placed between the pole piece and the sample in a standard SEM using a BSE detector like setup (Fig 2). The four SDD elements have an active area of $15 \mathrm{~mm}^{2}$ each resulting in a total of $60 \mathrm{~mm}^{2}$. This large active area and the annular geometry, where the detector elements are very close to the $\mathrm{x}$ ray source, lead to an extremely large solid angle of more than $1 \mathrm{sr}$. This is a value which is typically 100 times larger than a $10 \mathrm{~mm}^{2}$ detectors in a conventional setup. Therefore extremely high count rates can be achieved easily (with low probe currents) and can be processed with four separate electronic channels in parallel, leading to maximum output count rate of more than 1,100,000 cps. The best energy resolution is about $127 \mathrm{eV}$ at $\mathrm{Mn}-\mathrm{K} \alpha$.

These properties make the detector an ideal device for high speed mapping applications [3]. Fig. 3 shows a high speed $\mathrm{x}$-ray mapping of gold nanoparticles on a carbon film acquired at $5 \mathrm{kV}$ accelerating voltage with a probe current of $360 \mathrm{pA}$. The element mapping with a resolution of $600 \times 450$ pixels was taken in only $35 \mathrm{~s}$ total acquisition time, in order to find that the circular marked region of less than $10 \mathrm{~nm}$ width, includes 412 spectra, which collectively contain 2700 counts.

Fig. 4 shows a mapping of an ultrathin $(70 \mathrm{~nm})$ section of a magnetotactic bacterium poststainend with uranium containing "magnetosomes" (= iron oxide particles), which can be clearly seen in the image. This mapping was taken in about 800s acquisition time using a low accelerating voltage. The bacterium was part of a TEM sample analyzed in a SEM.

\section{References}

[1] H. Soltau et al., Microsc. Microanal. 15 (Suppl.2) (2009), 204

[2] R. Terborg, M. Rohde, Microsc. Microanal. 15 (Suppl.2) (2009), 206

[3] P. Kotula et al., Microsc. Microanal. 14 (Suppl.2) (2008), 116 
Acknowledgements:

The authors would like to thank Gerhard Wanner for providing the samples containing magnetotactic bacteria.

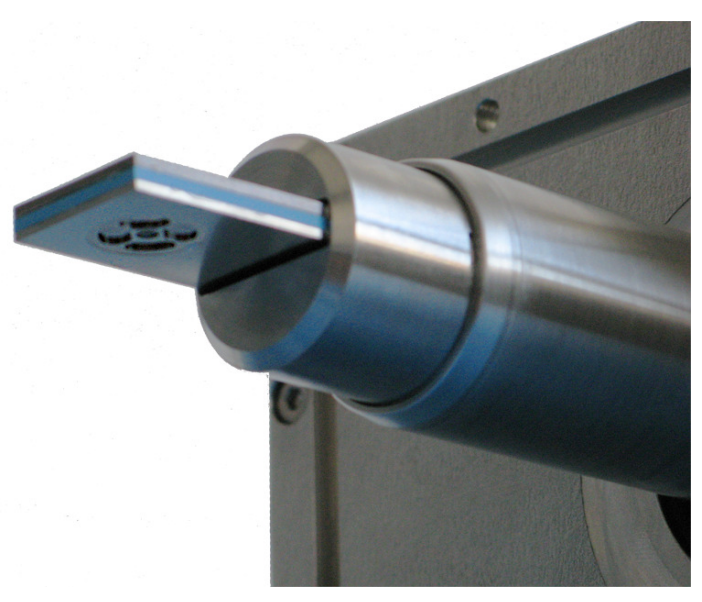

Fig. 1. Flat Quad detector (Quad XFlash 5060), which is placed between the pole piece and the sample.

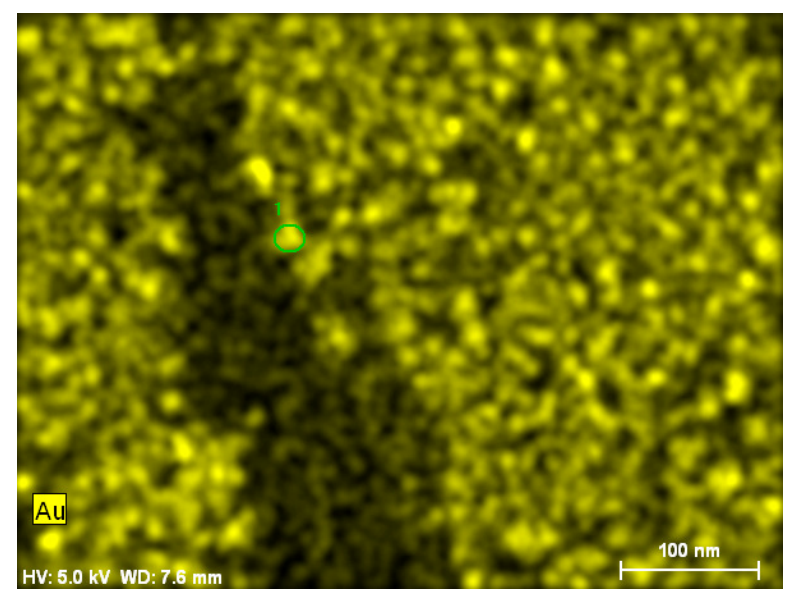

Fig. 3. X-ray mapping of gold nanoparticles on a carbon film. The $600 \times 450$ pixel image was taken in 35 s total acquisition time.

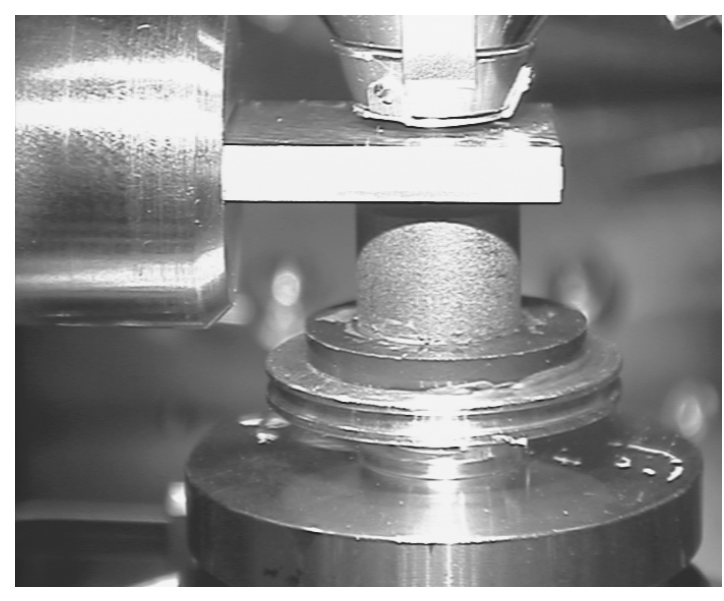

Fig. 2. Setup in a common SEM with pole piece (top) and sample (bottom).

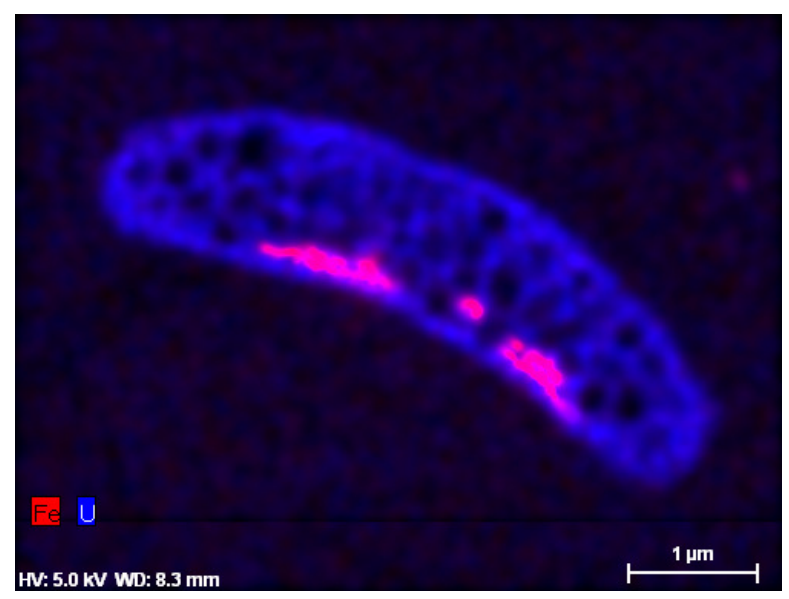

Fig. 4. Element mapping of a TEM sample (ultrathin section) showing a magnetotactic bacterium containing "magnetosomes" (= iron oxide particles). 